\title{
Transcriptional regulation of Zic 3 by heterodimeric AP-1(C-Jun/c-Fos) during Xenopus development
}

\author{
Sung-Young Lee ${ }^{1}$, Hyun-Shik Lee ${ }^{2}$, \\ Jin-Soo Moon ${ }^{1}$, Jong-II Kim ${ }^{1}$, Jae-Bong Park ${ }^{1}$, \\ Jae-Yong Lee ${ }^{1}$, Mae Ja Park \\ and Jaebong $\mathrm{Kim}^{1,4}$ \\ ${ }^{1}$ Department of Biochemistry \\ College of Medicine, Hallym University \\ Chuncheon, Kangwon-do 200-702, Korea \\ ${ }^{2}$ Laboratory of Protein Dynamics and Signaling \\ National Cancer Institute-Frederick \\ MD 21702, USA \\ ${ }^{3}$ Department of Anatomy \\ School of Medicine, Kyungpook National University \\ Daegu 700-422, Korea \\ ${ }^{4}$ Corresponding author: Tel, 82-33-248-2544; \\ Fax, 82-33-244-8425; E-mail, jbkim@hallym.ac.kr
}

Accepted 13 October 2004

Abbreviations: AP-1, activator protein-1; Zic3, zinc finger protein of the cerebellum

\begin{abstract}
The heterodimeric c-Jun/c-Fos, an activator protein-1 (AP-1) has been implicated in mesoderm induction (Dong et al., 1996; Kim et al., 1998) whereas the homodimer of c-Jun was reported to be involved in neural inhibition during the early development of Xenopus embryos. During the early vertebrate development AP-1 involvement in the neural induction is still not clearly understood. We report here that AP-1 has a role in Zic3 expression, a critical proneural gene and a primary regulator of neural and neural crest development (Nakata et al., 1997; Nakata et al., 1998). AP-1 was able to induce the Zic3 gene in a dose dependent manner but other homoor hetero-dimeric proteins, such as c-Jun/c-Jun, JunD/FosB or JunD/Fra-1 were not. The inhibition of AP-1 activity using morpholino antisenses of $c$-jun mRNAs blocked the Zic 3 expression induced by activin. In addition, co-injection of $c$-jun mRNA rescued the down-regulated Zic 3 expression. The promoter region of isolated Zic 3 genomic DNA was found to possess several consensus-binding site of AP-1. Thus, in the
\end{abstract}

functional assays, AP-1 could increase promoter activity of Zic3 gene. These findings suggest that proneural gene, Zic 3 may be regulated by heterodimeric AP-1(c-Jun/c-Fos) and it may have a role in activin signaling for the regulation of neural specific gene, Zic3.

Keywords: Activin; AP-1(c-Jun \& c-Fos); Xenopus development; Zic3

\section{Introduction}

The activator protein 1 (AP-1) transcriptional complex is composed of DNA binding proteins belonging to the protooncogenes, Jun and Fos and is the dimer formed between the Jun/Jun or Jun/Fos Family of 'bzip' transcription factors. The Jun family contains three proteins; C-Jun, JunB and JunD while the Fos family consists of five genes; c-Fos, FosB, $\triangle$ FosB, Fra-1 and Fra-2 (Tulchinsky et al., 2000; Vogt et al., 2001). AP-1 is required for activation of many genes that are induced by treatment of growth factors and cytokines (Shaulian et al., 2001, Kim et al., 2002, Kang et al., 2003). In mesoderm induction, AP-1 was demonstrated as a major downstream mediator in FGF signaling (Dong et al., 1996; Kim et al., 1998) and also in BMP-4 signaling and in BMP-4 expression (Xu et al., 1996; Kim et al., 1998). BMP is a key morphogen functioning in neural inhibition and epidermal differentiation as well as ventral mesoderm specification (Graff et al., 1994; Jones et al., 1996). However, AP-1 involvement has not been reported for the neural specification during the early vertebrate development.

The Zic family was originally identified as a group of genes encoding zinc finger proteins in mouse cerebella (Aruga et al., 1994; Aruga et al., 1996; Brown et al., 2003). Also, the Zic genes were isolated in human (Herman et al., 2002), chick, (Warner et al., 2003) Xenopus (Nakata et al., 1997; Nakata et al., 1998), Zebrafish (Grinblat et al., 2001), and Drosophilia as odd-paired (opa) gene (Cimbora et al., 1995; Aruga et al., 1996). These zinc finger proteins share a highly conserved domain consisting of five tandemly repeated $\mathrm{C}_{2} \mathrm{H}_{2}$-type zinc finger motifs, which have a role of DNA binding. In Xenopus, four Zic genes have been isolated and investigated for their properties. Not only in their expression patterns but also in their functions, these Zic genes have several 
similarities and differences (Nakata et al., 1997; Nakata et al., 1998). Specially, one of these, Zic3 gene induces neural crest and proneural markers when overexpressed in animal cap explants. In addition, onset of the Zic3 expression is earlier than most proneural genes and followed chordin expression (Nakata et al., 1997). These data indicated that Zic3 have a role as a primary regulator both in neural and neural crest development. Recently, Zic3 was shown to be involved in the left-right specification of the Xenopus embryo (Kitaguchi et al., 2000; Herman et al., 2002) and $\mathrm{Vg} 1 /$ activin signaling is involved in this Zic3's effect (Kitaguchi et al., 2000; Weber et al., 2003).

While investigating the roles of AP-1 in Xenopus animal cap explant cultures, we found that AP-1 might have a role as a positive regulator of Zic3 in neural specification. Here, we report the microinjection of a heterodimeric AP-1 (c-Jun/c-Fos) transcription factor but not (C-Jun/C-Jun, JunD/FosB or JunD/Fra-1) leading to the expression of proneural gene, Zic3. Further investigations of loss-of-function using morpholino antisenses for c-jun mRNA and of the isolated promoter region Zic3 genomic DNA, suggest that proneural gene, Zic3 may be regulated by heterodimeric AP-1(c-Jun/c-Fos) and AP-1 may have a role in activin signaling for the regulation of neural specification.

\section{Materials and Methods}

\section{Isolation of Xenopus Zic3 genomic sequence}

Genomic clones for Zic3 were isolated by screening a Xenopus $\mathrm{EEMBL} 4$ genomic library (Clontech) with a PCR amplified cDNA probe that corresponds to segment from base pair 91 to 271 of Xenopus Zic3 cDNA (Genebank AB005292). Approximately $5 \times 10^{5}$ clones were screened with a ${ }^{32} \mathrm{P}$-labeled probe or $E C L$ system in accordance with the manufacture's (Amersham) instruction. Thirty putative clones were isolated and analyzed by PCR using the same primers (91-271 nt) used for probe generation. Six clones were selected, which produced a distinct band. We analyzed by Southern hybridization with a Zic3 cDNA probe, and by digestion with the restriction enzymes. One clone was selected, the fragments generated by $\mathrm{XhOl}$ and HindIII were subcloned into pGEM7 (Promega). The $2.2 \mathrm{~kb}$ fragment was further analyzed by complete DNA sequence analysis. Both strands of DNA have been sequenced using automatic sequencing (accession number AF179297).

\section{Plasmid constructs}

Different lengths of the Zic3 promoters were cloned into the luciferase reporter plasmid of pGL2-Basic (Promega, Madison, WI). The various Zic3 promoter constructs were made by cloning $1.8 \mathrm{~kb}$ of the promoter into the Sacl and blunt-ended Bglll-Xba I site of pGL2-Basic and subsequently generating smaller constructs by using specific restriction endonucleases to remove $5^{\prime}$ portions of the promoter (Figure 3 ). -259/ARE Zic3 promoter construct was made by insertion of activin responsive enhancer region (Weber et al., 2003) behind -259 Zic3 Luciferase.

\section{Embryo injection and explant culture}

Xenopus laevis embryos were obtained by artificial fertilization (Smith et al., 1983). Developmental stages were designated according to Nieuwkoop and Faber (Nieuwkoop et al., 1967). The vitelline membranes were removed by immersing the embryos in the thioglycolic acid solution. Embryos at the one cell stage or two-cell stage were injected in the animal pole with messenger RNA or DNA as descried in the figure legends. Animal caps were dissected from the injected embryos at stage 8-9 and cultured to various stages in $67 \%$ Leibovitzs L-15 medium (GIBCO/BRL) with L-glutamine $(0.3 \mathrm{mg} / \mathrm{ml}), 7 \mathrm{mM}$ Tris- $\mathrm{HCl}(\mathrm{pH} 7.5)$ and gentamicin $(50 \mathrm{~g} / \mathrm{ml})$ for one or two days. Activin were treated in $\mathrm{L}-15$ medium, final concentration 25 $\mathrm{ng} / \mathrm{ml}$ in the presence of $1 \mathrm{mg} / \mathrm{ml}$ bovine serum albumin.

\section{In vitro transcription}

All synthetic mRNAs used for microinjection were produced by in vitro transcription. The c-jun cDNA was inserted in the pGEM (Rauscher et al., 1988) and c-fos were sub-cloned into the pSP65 vector (Curran et al., 1987). Each of the cDNAs were linearized and used for in vitro synthesis of capped mRNA using in vitro transcription kit (Ambion) in accordance with the manufacture's instructions. The synthetic RNA was quantified by ethidium bromide staining in comparison with a standard RNA.

\section{RNA isolation and reverse transcription - PCR}

Total RNA was extracted from whole embryos or cultured explants with TRIzol reagent (Life Technologies, Inc.) following the manufacturers instructions. RT-PCR was performed with a Superscript pre-amplification system (Life Technologies, Inc.). PCR was performed as follows: first, a denaturation step of $94^{\circ} \mathrm{C}$ for $5 \mathrm{~min}$; second, $94^{\circ} \mathrm{C}$ for $1 \mathrm{~min}$; each annealing temperature, for $1 \mathrm{~min} ; 72^{\circ} \mathrm{C}$ for $1 \mathrm{~min}$; third, repeat second step 19-28 cycles of amplification was performed as described at the Xenopus Molecular Marker Resource (XMMR; University of Texas). All the primer sets of RT-PCR described at the 
XMMR were applied.

\section{Luciferase assay}

We have used Zic3 promoter-Luc in this study. Zic3 promoter-Luc containing about $1.8 \mathrm{~kb}$ genomic DNA was inserted into a luciferase construct with the minimal promoter sequences from albumin gene (Dong et al., 1994; Dong et al., 1995). Zic3 promoter-Luc plasmid DNA was injected at $20 \mathrm{pg}$ per embryo alone or together with various mRNAs into one-cell-stage embryos or two blastomeres of two-cell-stage embryos. After injection, animal caps were removed at stage 8-9 and cultured in the presence or absence of activin until harvesting at stage 13. Four to five animal caps per group were pooled and homogenized to prepare the cell extract. Zic3 promoter-dependent luciferase activity of the extract was measured with luminometer at $15 \mathrm{~s}$ after mixing of the extract and the Promega luciferase assay reagent. Activity was expressed as integrated light units (Dong et al., 1995).

\section{Morpholino oligos}

We used morpholino oligos (Gene Tools LLC) for antisense oligodeoxynucleotide. The base composition of antisense oligodeoxynucleotide were 21-mer morpholino 5'CTGGAGCTTATGTCAGTGTGA3' (MO-jun54) and 25-mer morpholino 5'GTAGTTTCCATCTTTGCGTTCATAC3' (MO-jun55). These oligos were designed to bind to complementary sequences found in two kinds of Xenopus c-jun mRNAs (Knochel et al., 2000) and the binding prevents translation of those $c$-jun mRNAs. 5' Morpholino oligos have substitutions of the riboside moieties with nitrogen-containing morpholine moieties and are phosphorodiamidate linked (Summerton et al., 1997). Oligos were resuspended in sterile water and injected in doses of $40 \mathrm{ng}$ per embryos.

\section{Results and Discussion}

\section{Heterodimeric AP-1(C-Jun/C-Fos) induces XZic 3 in animal cap explants}

Previously, it has been demonstrated the involvement of AP-1 in mesoderm induction as well as in neural inhibition during the vertebrate early development (Dong et al., 1996; Kim et al., 1998; Knochel et al., 2000; Peng et al., 2002). However, the roles of AP-1 have not been investigated for the neural induction. In order to examine the roles of AP-1 in neural specification, the expression of proneural gene, Zic3 expression was investigated. Zic3 expression was selected because onset of the Zic3 expression is earlier than most proneural genes and Zic3 gene induces neural crest and proneural markers when overexpressed in animal cap explants (Nakata et al., 1997).

A

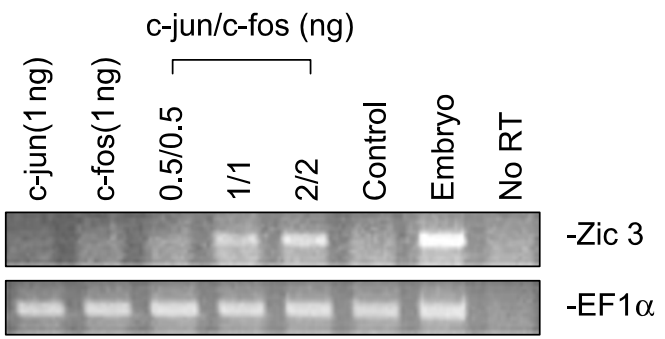

B

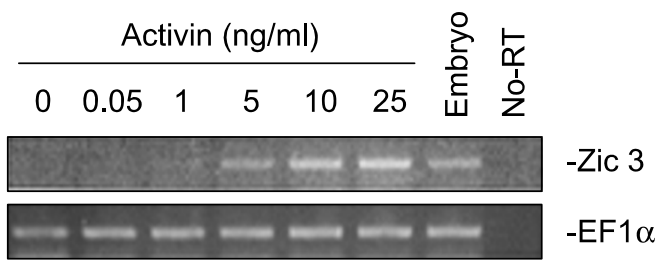

C

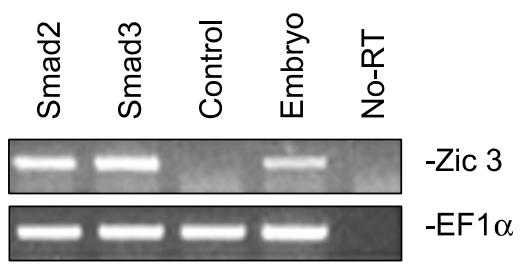

Figure 1. Heterodimeric c-Jun and $c$-Fos induces Zic3 gene in a dose dependent manner. A: Co-injection of c-jun and c-fos mRNA induced Zic3 gene in a dose-dependent manner. c-Jun or c-Fos alone did not induce the Zic3 expression. Embryos at one or two cell stages were injected in animal pole regions with mRNAs of the following: lane 1, mRNA of c-jun (1 ng); lane 2, c-fos (1 ng); lane 3, c-jun (0.5 ng) plus c-fos $(0.5 \mathrm{ng})$; lane 4 , c-jun ( $1 \mathrm{ng})$ plus $c$-fos (1 $\mathrm{ng})$; lane 5 , c-jun $(2 \mathrm{ng}$ ) plus c-fos $(2 \mathrm{ng})$; lane 6 , control $\beta$-galactosidase $(1 \mathrm{ng})$. The animal caps were dissected from the injected embryos at stages 8.5-9 and cultured until stage 11. RNAs were isolated from animal cap explants and analyzed by RT-PCR to determine the expression of Zic3 and the equal loading control EF1 $\alpha$ gene using ethidium bromide staining. Embryos at stage 11 were used as a positive control (lane 7), and the same embryo sample processed for RT-PCR in the absence of reverse transcriptase (-rt) was used as a negative control (lane 8). B: Zic3 gene was induced by activin in a dose-dependent manner. The animal caps were dissected from the embryos at stages 8.5-9 and cultured in the absence (lane 1) or in the presence of different dosages of activin ( 0.05 to $25 \mathrm{ng} / \mathrm{ml}$, lane 2-6) until stage 11. C: Smad2 and Smad3, the mediators of activin signaling, also induced the Zic3 gene. Embryos at one or two cell stages were injected with mRNAs of the following: lane 1, mRNA of Smad2 (1 $\mathrm{ng}$ ); lane 2, Smad3 (1 $\mathrm{ng})$; lane 3, control $\beta$-galactosidase (1 $\mathrm{ng}$ ). RT-PCR analysis were performed as described in Figure $1 \mathrm{~A}$. 
Embryos were injected with RNA encoding c-jun and/or $c$-fos at one or two cell stages. The animal pole tissue was then dissected at the blastula stage (stage 8-9) and incubated until stage 11. RT-PCR analysis was then performed to examine the expression of Zic3 as described in Materials and Methods. Injection of $\beta$-galactosidase $(\beta$-gal) as control RNA, $c$-jun, or c-fos RNA alone did not induce any Zic3 gene expression (Figure 1A). On the other hand animal caps from embryos injected with $c$-jun and c-fos RNAs together clearly induced Zic3 expression (Figure 1A). Moreover, the animal cap explants from the embryos injected with other heterodimeric AP-1 components of JunD/Fra-1 or JunD/FosB RNA combinations did not induce Zic3 gene (data not shown). The results clearly demonstrated that heterodimeric AP-1 (c-Jun and C-Fos) is sufficient to induce Zic3 gene in animal cap explants.

Previously, the involvement of AP-1 in mesoderm induction was demonstrated as a major downstream mediator of FGF signaling (Dong et al., 1996; Kim et al., 1998). However, FGF signaling alone in animal cap explants does not induce Zic3 gene expression. Therefore, Zic3 expression by heterodimeric AP-1 (c-Jun and C-Fos) was somewhat unexpected result. Zic3 expression in animal cap explants is similar to activin activity, but different from FGF activity.

We confirmed Zic3 induction by activin (Figure 1B) and the signal mediators of activin signaling (Smad2 and Smad3) (Figure 1C). Embryos were injected with $\beta$-gal or RNA encoding Smad2 or Smad3. The animal pole tissues were dissected at the blastula stage (stage 8-9) and incubated until stage 11. The animal cap tissues from embryos injected with $\beta$-gal RNA were incubated in the absence or in the presence of different dosages of activin protein. Zic3 gene expression was induced in activin treated animal cap explants in a dose dependent manner (Figure 1B) as well as in the animal cap explants obtained from the embryos injected with RNA encoding Smad2 or Smad3 (Figure 1C). Taken together, the results suggest that heterodimeric AP-1 (C-Jun and C-Fos) may be involved in neural specification of Zic3 induction in activin signaling.

The blocking of AP-1 decreases the expression of Zic 3 gene induced by activin

Co-expression of C-Jun and C-Fos induced Zic3 gene expression and the effect was similar to the activity of activin signaling in animal cap explants, but different from that of FGF signaling. In order to examine the Zic3 regulation by heterodimeric AP-1(c-Jun/cFos) in activin signaling, the effect on the AP-1 function was examined in the animal cap explant culture system of Xenopus embryos.
For effective blocking of AP-1 activity in Xenopus embryos, we used morpholino oligos of $c$-jun mRNAs (MO-C-Jun54 and MO-C-Jun55) as described in Materials and Methods. Morpholino oligos have a function of antisense by preventing translation of mRNA. For the reasons of non-toxicity, stability and permeability, advanced antisense structural type of morpholino oligos recently have been used (Gene Tools LLC). Here, we used MO-c-Jun54 and MO-c-Jun55. These morpholinos were designed to bind to $5^{\prime}$ untranslated regions including the $A U G$ translational start sites in two kinds of Xenopus c-jun mRNAs (cJun54 and C-Jun55). We injected $40 \mathrm{ng}$ of MO-Jun54 and MO-Jun55 (MO54/55) into one or two cell stage, then dissected animal caps at stage 8-9 and cultured them in the presence or absence of activin. Then we analyzed the Zic3 expression using RT-PCR.

As expected, the blocking of AP-1 activity by $\mathrm{MO}-\mathrm{C}-J u n s$ resulted in down-regulation of Zic3 gene induced by activin (Figure 2A). In order to confirm that

A

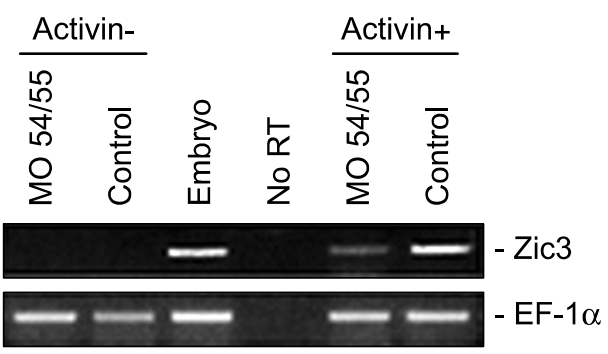

B

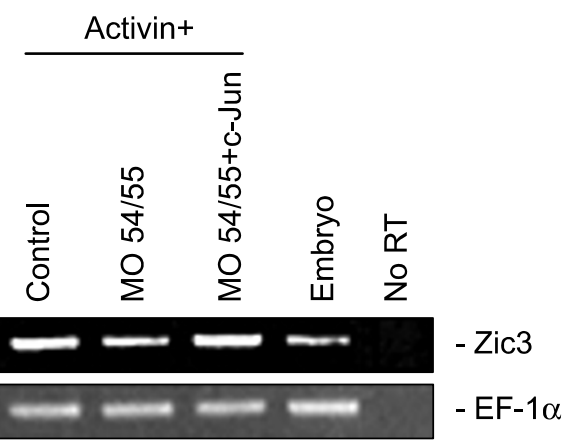

Figure 2. The blocking of AP-1 decreases the expression of Zic3 gene induced by activin. (A) Blocking of AP-1 activity decrease Zic3 gene induced by activin. Animal pole tissues injected with morpholino c-Juns [M0-54 (40 ng) and M0-55 (40 ng) C-Juns, per embryos] were cultured in the presence or absence of activin $(25 \mathrm{ng} / \mathrm{ml})$. Zic3 gene induction was examined at stage 11 by RT-PCR as described in Figure 1A. M0-c-Juns inhibited Zic3 expression induced by activin. (B) The Zic3 expression inhibited by MO-C-Juns was rescued by co-injection of rat c-jun mRNA. Animal pole tissue injected with morpholino c-Juns alone or co-injection of c-jun mRNA (1 ng) were cultured in the presence of activin $(25 \mathrm{ng} / \mathrm{ml})$. Zic3 gene expression was examined at stage 11 by RT-PCR as described in Figure $1 \mathrm{~A}$. 
the blocking activities of MO-c-Juns against endougenous c-jun mRNAs were specific, we tested whether co-injection of rat c-jun mRNA could rescue the Zic3 expression decreased by MO-c-Juns. The overexpression of rat $c$-jun indeed rescue the Zic3 expression decreased by MO-C-Juns, suggesting that MO-c-Juns blocked against the endougenous $c$-jun mRNAs in specific mood (Figure 2B). Two kinds of c-jun mRNAs have been reported in Xenopus em- bryos (Knochel et al., 2000). Interestingly, we found that one form of c-Jun Morpholino alone was not effective for blocking of c-Jun activity, indicating that both of mRNAs may be functioning during the early neural specification caused by activin signaling in Xenopus embryos. Taken together, the results suggested that heterodimeric AP-1 (c-Jun and c-Fos) is involved in Zic3 expression induced by activin signaling.

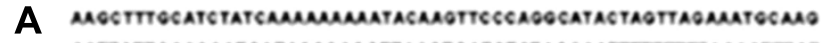

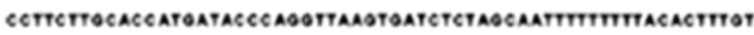
- TACATrTocart

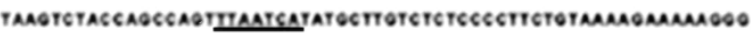
CMATOC TTTOATMATTOOOAOTCAMATACAOTTATOCTOCACOOMUOOCTCACTTACOA

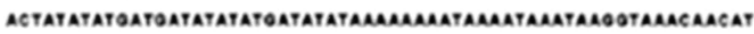

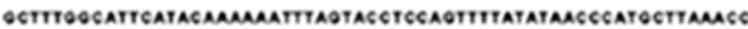

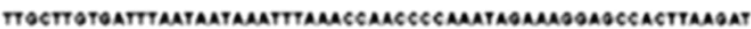

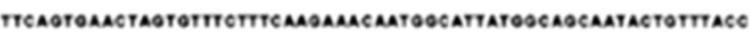

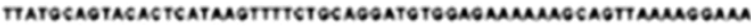
SCTAOTOCTTHAATSAONOSCAOAACTOCTCATTCAOTAACTCATOAAC TOCMUACTO TTCTOTTOCTTTOTTCTCAMAOCTCTTOSAOTTTTHATAOAOAATTOCTOAOACATAMC

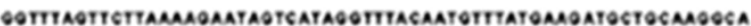
TTCTCAOATTATAOAMTOTOTOOOAMCATATTTOTTCATTCMAOTATCTOTTMACTSTTO MOTCETOOMAOATOATOCEMACATCTITCEACAMTCEATCC TOOOCACTTOCAOCAMC TMMOOOTTMUC TTACC TOCAMACACTCAMCAOCAOTAOACCMATCMMOOCTOTOATAT TAOTOOCTCTOCEATATTCAOTOCTMUCTCTOTCAMTCMOAOTTCATAQOCAMATOSO TOCETOSOOTTOSOTTCTTTOACACTCCCCEACTOAOTTECTATTOOTOCAATTCAOA TOCSTCSTOAOTTOOTTATOTOTOAOCAOTEAQTEATTOACTTATCAOTCSMAOQAC ATA

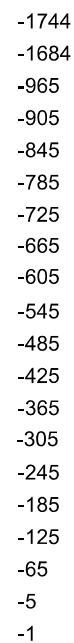

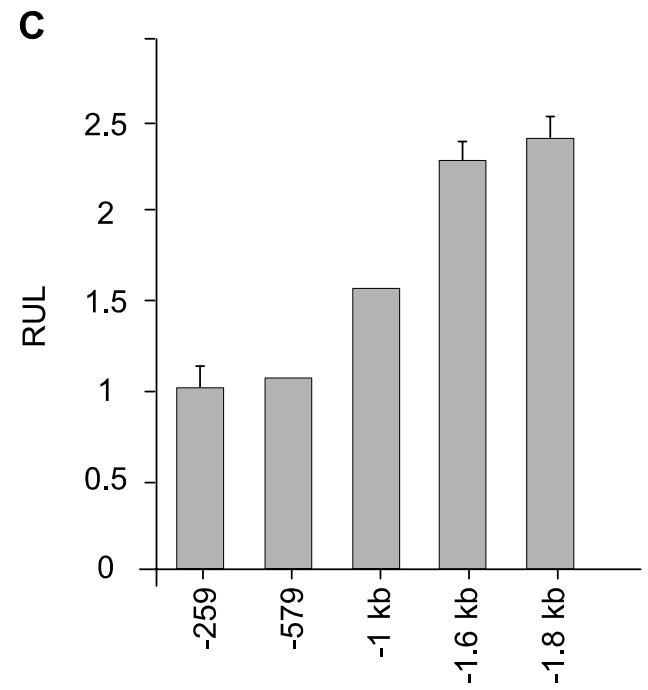

B

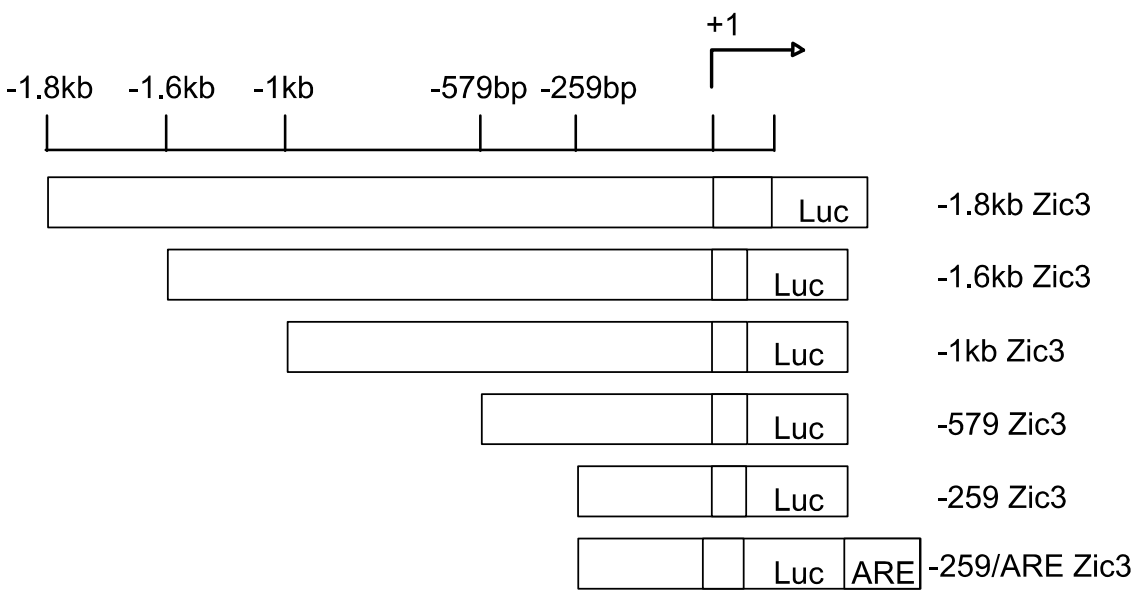

Figure 3. The isolated '5' flanking region of Xenopus Zic3 gene. (A) DNA sequence of Xenopus Zic3 5' flanking region (GeneBank Accession No. AF179297). Sequence motifs for the putative AP-1 binding sites are indicated as underlined bold letters. The numbers refer to the position relative to the transcriptional start site $(+1)$. (B) A schematic diagram illustrating the Zic3 promoter-reporter deletion constructs. Serial deletion constructs of the Zic3 promoter were subcloned into pGL2-basic plasmid. The transcription start site is indicated at +1 and Luc box represents the luciferase gene. ARE indicates activin responsive enhacer region which was published by Weber et al., 2003. (C) Relative luciferase activity of $5^{\prime}$ serieal deletion constructs of genomic Zic3. Basal activity in animal cap was a little decreased as promoter shortens. Zic3 promoter-Luc plasmid DNAs were injected at $20 \mathrm{pg}$ per embryo into one-cell-stage embryos or two blastomeres of two-cell-stage embryos. After injection, animal caps were removed at stage 8-9 and cultured until harvesting at stage 13 . Four to five animal caps per group were pooled and homogenized to prepare the cell extract. The relative luciferase activity of the extract was measured with luminometer at $15 \mathrm{~s}$ after mixing of the extract and the Promega luciferase assay reagent. The relative activity was expressed as integrated light units. 


\section{Isolation of 5 ' flanking region of Xenopus Zic3 gene}

Zic3 gene was induced by heterodimeric AP-1 (c-Jun and C-Fos) and Zic3 expression by activin signaling was blocked by MO-c-Juns. In order to examine the transcriptional regulation of Zic3 gene by heterodimeric AP-1 (c-Jun and c-Fos) in the isolated genomic DNA, we isolated genomic Zic3 gene from the Xenopus muscle genomic library.

The Xenopus muscle genomic library was screened with the Zic3 5' UTR specific probe (see details in Materials and Methods). A 2041 bp genomic fragment containing Zic3 $5^{\prime}$ UTR region was subcloned and sequenced. Figure $3 \mathrm{~A}$ shows a schematic diagram of the genomic organization of Xenopus Zic3 gene. This genomic sequence covered $100 \mathrm{bp}$ of coding region, $130 \mathrm{bp}$ of UTR region and about $1.8 \mathrm{~kb}$ of $5^{\prime}$ flanking region (Gene bank accession number AF179297). Many putative transcriptional regulatory elements were identified within the $5^{\prime}$ flanking region of Zic3. Interestingly, we identified five putative AP-1 binding sites (Figure $3 A$ ). The presence of putative binding site for the AP-1 supports that AP-1 transcriptional factor may be involved in the regulation of Zic3 gene.
In order to further study of transcriptional regulation of Zic3, we constructed the series of Zic3 5' deletion constructs reaching to position -259 relative to the transcription initiation site (Figure 3B) and tested basal activity of these constructs (Figure $3 \mathrm{C}$ ). The basal activities of $-1.8 \mathrm{~kb}$ and $-1.6 \mathrm{~kb}$ Zic3 constructs were high and similar. The basal activities of other deletion constructs were decreased (Figure $3 \mathrm{C}$ ).

\section{Activation of Zic3 promoter activity by AP-1 (c-Jun/c-Fos)}

Zic3 gene was induced by heterodimeric AP-1 (c-Jun and C-Fos). In order to examine whether the isolated Zic3 promoter was also regulated by heterodimeric AP-1 (c-Jun and c-Fos), the Zic3 promoter-Luc reporter genes were co-injected with the mRNAs encoding c-Jun and c-Fos or injected with other AP-1 components at one or two cell stage. The animal pole tissue was then dissected at stage 8-9 and incubated until stage 13 to measure the reporter activities.

As expected, the relative reporter activity of -1.6 $\mathrm{kb}$ of Zic3 promoter was enhanced by co-injection of $c$-jun and c-fos mRNAs together. On the other hand,
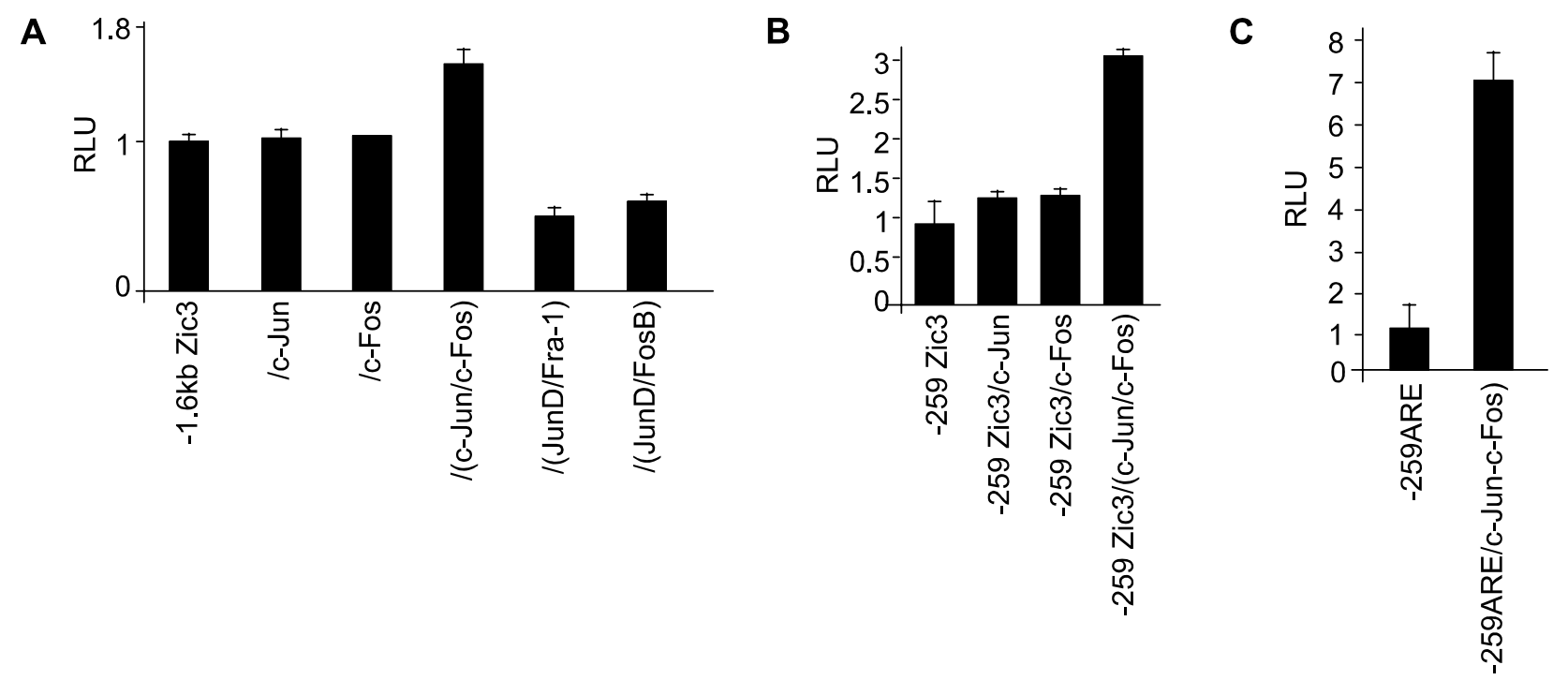

Figure 4. Heterodimeric c-Jun and C-Fos increases Zic3 promoter activity. (A) The embryos were co-injected at one cell stage into the animal pole region with $20 \mathrm{pg}$ per embryo and indicated mRNAs (1 $\mathrm{ng}$ per embryo) with Zic3 promoter-Luc reporter construct of -1.6 kb Zic3 promoter. Animal caps were dissected from the embryos at stage 8.5 and cultured until stage 11 . The injected mRNAs included mRNAs of c-jun, c-fos, jun $D$, fra-1 and fosB. Animal pole tissues were cultured until stage 13 and luciferase activities were measured as described in Figure 3 . The reporter activity of $-1.6 \mathrm{~kb}$ Zic3 promoter construct was activated only by co-injection of c-jun and c-fos RNA together. However c-jun or c-fos alone did not activate the reporter activity of $-1.6 \mathrm{~kb}$ Zic3 promoter construct. Moreover co-injection of other AP-1 components of Jun D/Fra-1 or JunD/FosB reduced the reporter activity of $-1.6 \mathrm{~kb}$ construct. (B) The embryos were co-injected at one cell stage into the animal pole region with $20 \mathrm{pg}$ of -259-Luc reporter gene and indicated mRNAs (1 $\mathrm{ng}$ per embryo). Animal pole tissues were cultured until stage 13 and luciferase activities were measured as described in Figure 3. The reporter activity of -259-Luc reporter construct was increased by co-injection of c-jun and $c$-fos, but not by $c$-jun or c-fos alone. (C) The embryos were co-injected at one cell stage into the animal pole region with $20 \mathrm{pg}$ of -259ARE-Luc reporter gene and indicated mRNAs (1 ng per embryo). Animal pole tissues were cultured until stage 13 and luciferase activities were measured as described in Figure 3. The shortest Zic3 promoter, -259-Luc reporter gene containing ARE was also increased by co-injection of $c$-jun and c-fos. 
animal caps from embryos injected with $\beta$-galactosidase $(\beta$-gal) as control RNA, $c$-jun or $c$-fos RNA alone did not increase the reporter activity (Figure $4 \mathrm{~A})$. Moreover, the animal cap explants from the embryos injected with other heterodimeric AP-1 components of junD/fra-1 or junD/fosB RNA combinations did not increase the reporter activity. In addition, the reporter activity of shortest 5 ' deletion construct of -259 Zic3 promoter-Luc was also enhanced only by co-injection of c-jun and c-fos (Figure 4B). Although whether the enhancement of the reporter gene activity by heterodimeric AP-1 is direct or indirect, is not conclusive, the results were consistent with Zic3 induction experiment as shown in Figure 1C, suggesting that the isolated Zic3 promoter may contain the region regulated by $A P-1$.

A significant level of activity enhancement by heterodimeric AP-1 (c-Jun/c-Fos) remained even in the -259 Luc construct. Recently, an activin responsive enhancer (ARE) region, which was located in the Zic3 first intron, was identified as one of Zic3 gene regulatory element (Weber et al., 2003). In order to examine the effect of $A R E$ region for heterodimeric AP-1, we constructed -259 Luc-containing ARE region (-259ARE) (Figure 3B). Interestingly, the reporter activity enhancement containing ARE in -259 Zic3 Luc construct was greater than that of -259 Zic3 Luc construct by heterodimeric AP-1 (c-Jun/c-Fos), supporting the results of AP-1 involvement in Zic3 expression by activin signaling shown in Figure 2 .

In this paper, we show, for the first time, that heterodimeric AP-1 (c-Jun/c-Fos) induces the expression of Zic3 gene, a primary proneural gene in animal cap explants. Since Zic3 gene has significant roles both in neural and neural crest development in Xenopus embryo, the results suggest that heterodimeric AP-1 (c-Jun/c-Fos) may have a role in neural specification during the early vertebrate development. In addition, heterodimeric AP-1 (c-Jun and C-Fos) is involved in Zic3 expression induced by activin signaling by using specific antisense Morpholino c-Juns. The involvement of heterodimeric AP-1 in Zic3 expression by activin was somewhat unexpected results since heterodimeric AP-1 has been reported to be an essential component of FGF signaling, however, AP$1 /$ Jun has been reported not to mediate mesoderm induction by activin. AP-1 involvement in mesoderm and neural specification may be different. Although the detail studies of AP-1 involvement in activin activity is beyond the scope of this paper, it will be interesting to further investigate the role of AP-1 in activin signaling during the early development of Xenopus embryos. By screening of $1.8 \mathrm{~kb} 5^{\prime}$ flanking region of Zic3 gene and the reporter activity shown to be enhanced by heterodimeric AP-1 (c-Jun/c-Fos), provided a strong supports for the AP-1 involvement in Zic3 expression. Other heterodimeric AP-1 components of AP-1 did not increase the activity of Zic3 promoter nor Zic3 expression. The results suggest that Zic3 regulation by $\mathrm{AP}-1$ is dependent on heterodimeric AP-1 consisted of $\mathrm{C}-J$ un and C-Fos, not on other AP-1 components (JunD/FosB and JunD/ Fra-1). Various combinations of different AP-1 components were found to have distinctive roles during the early Xenopus development (unpublished data). Taken together, these results demonstrate that heterodimeric AP-1 (c-Jun/c-Fos) is a key molecule in Zic3 expression in the neural specification during the early development of vertebrate embryos.

\section{Acknowledgement}

We thank Dr. Makoto Asashima for activin protein; Dr. Tom curran for c-jun and c-fos cDNAs. This research was supported by Korea Research Foundation Grant (KRF-2001-015-FP0038).

\section{References}

Aruga J, Yokota N, Hashimoto M, Furuichi T, Fukuda M, Mikoshiba K. A novel zinc finger protein, zic, is involved in neurogenesis, especially in the cell lineage of cerebellar granule cells. J Neurochem 1994;63:1880-90

Aruga J, Nagai T, Tokuyama T, Hayashizaki Y, Okazaki Y, Chapman VM, Mikoshiba K. The mouse zic gene family. Homologues of the Drosophila pair-rule gene odd-paired. J Biol Chem 1996;271:1043-7

Benedyk MJ, Mullen JR, DiNardo S. Odd-paired : A zinc finger pair-rule protein required for the timely activation of engrailed and wingless in Drosophila embryo. Genes Dev 1994;8:105-17

Brown LY, Kottmann AH, Brown S. Immunolocalization of Zic2 expression in the developing mouse forebrain. Gene Expr Patterns 2003;3:361-7.

Cimbora DM, Sakonju S. Drosophila midgut morphogenesis requires the function of segmentation gene odd-paired. Dev Biol 1995;169:580-95

Curran T, Gordon MB, Rubino KL, Sambucetti LC. Isolation and characterization of the c-fos(rat) cDNA and analysis of post-translational modification in vitro. Oncogene 1987;2:7984

Dong Z, Birrer MJ, Watts RG, Matrisian LM, Colburn NH. Blocking of umo promoter-induced AP-1 activity inhibits induced transformation in JB6 mouse epidermal cells. Proc Natl Acad Sci USA 1994;91:609-13

Dong Z, Lavrovsky V, Colburn NH. Transformation reversion induced in JB6 RT10 cells by AP-1 inhibitors. Carcinogenesis 1995;16:749-56

Dong Z, Xu RH, Kim J, Zhan SN, Ma WY, Colburn NH, Kung H. AP-1/jun is required for early Xenopus development and mediates mesoderm induction by fibroblast growth factor but not by activin. J Biol Chem 1996;271:9942-6 
Graff JM, Thies RS, Song JJ, Celeste AJ, Melton DA. Studies with a Xenopus BMP recpetor suggest that ventral mesoderm-inducing signal override dorsal signals in vivo. Cell 1994;79:169-79

Grinblat $Y$, Sive H. Zic gene expression marks anteroposterior pattern in the presumptive neurectoderm of the Zebrafish gastrula. Dev. Dynamics 2001;222:688-93

Hemmati-Brivanlou A, Melton DA. A truncated activin receptor inhibits mesoderm induction and formation of axial structures in Xenopus embryos. Nature 1992;359:609-14

Herman GE, El-Hodiri HM. The role of Zic3 in vertebrate development. Cytogenet. Genome Res 2002;99:229-35

Jones CM, Dale L, Hogan BL, Wright CV, Smith JC. Bone morphogenetic protein-4 (BMP-4) acts during gastrula stages to cause ventralization of Xenopus embryo. Development 1996;122:1545-54

Kang SH, Song JH, Kang HK, Kang JH, Kim SJ, Kang HW, Lee YK, Park DB. Arsenic trioxide-induced apoptosis is independent of stress-responsive signaling pathways but sensitive to inhibition of inducible nitric oxide synthase in HepG2 cells. Exp Mol Med 2003;35:83-90

Kim J, Lin JJ, Xu RH, Kung HF. Mesoderm induction by heterodimeric AP-1 (c-Jun and c-Fos) and its involvement in mesoderm formation through the embryonic fibroblast growth factor/Xbra autocatalytic loop during the early development of Xenopus embryos. J Biol Chem 1998;273: 1542-50

Kim J, Ault KT, Chen HD, Xu RH, Rho DH, Lin MC, Park MJ, Kung HF. Transcriptional regulation of BMP-4 in the Xenopus embryo: Analysis of genomic BMP-4 and its promoter. Biochem Biophys Res Commun 1998;516-30

Kim JW, Ahn WH. C/EBP binding activity to site $F$ of the rat GLUT2 glucose transporter gene promoter is attenuated by C-Jun in vitro. Exp Mol Med 2002;34:379-84

Kitaguchi T, Nagai T, Nagata K, Aruga J, Mikoshiba K. Zic3 is involved in the left-right specification of the Xenopus embryo. Development 2000;127:4787-95

Knochel S, Schuler-Metz A, Knochel W. c-Jun (AP-1) activates BMP-4 transcription in Xenopus embryos. Mech Dev 2000;98:29-36.
Nakata K, Nagai T, Aruga J, Mikoshiba K. Xenopus Zic3, a primary regulator both in neural and neural crest development. Proc Natl Acad Sci USA 1997;94:11980-5.

Nakata K, Nagai T, Aruga J, Mikoshiba K. Xenopus Zic family and its role in neural and neural crest development. Mech Dev 1998;75:43-51.

Nieuwkoop PD, Faber J. Normal Table of Xenopus laevis, 2nd Ed, North-Holland, Amsterdam. 1967

Peng $Y$, Xu RH, Mei JM, Li XP, Yan D, Kung HF, Phang JM. Neural inhibition by C-Jun as a synergizing factor in bone morphogenetic protein4 signaling. Neuroscience 2002;109: 657-64

Rauscher FJ, Voulalas PJ, Franza BR, Curran T. Fos and Jun bind cooperatively to the AP-1 site: reconstitution in vitro. Genes Dev 1988;2:1687-99

Shaulian E, Karin M. AP-1 in cell proliferation and survival. Oncogene 2001;20:2390-2400

Smith JC, Slack JM. Dorsalization and neural induction: properties of the organizer in Xenopus laevis. J Embryol Exp Morphol 1983;78:299-317.

Summerton J, Weller D. Morpholino antisense oligomers: design, preparation, and properties. Antisense Nucleic Acid Drug Dev 1997;7:187-95 Review

Tulchinsky E. Fos family members : regulation, structure and role in oncogenic transformation. Histol. Histopathol 2000;15: $921-8$

Vogt PK. Jun, the oncoprotein. Oncogene 2001;20:2365-77

Warner SJ, Hutson MR, Oh SH, Gerlach-Bank LM, Lomax $\mathrm{MI}$, Barald KF. Expression of ZIC genes in the development of the chick inner ear and nervous system. Dev Dyn 2003;226:702-12.

Weber JR., Sokol SY. Identification of a phylogenetically conserved activin-responsive enhancer in the Zic3 gene. Mech Dev 2003;120:955-64

Xu RH, Dong Z, Maeno M, Kim J, Suzuki A, Ueno N, Sredni $\mathrm{D}$, Colburn NH, Kung $\mathrm{H}$. Involvement of Ras/Raf/AP-1 in BMP-4 signaling during Xenopus embryonic development. Proc Natl Acad Sci USA 1996;93:834-8 